\title{
Malignant tumours of the external ear
}

\author{
Cengiz H Karsli BSc MD, Oleh M Antonyshyn MD FRCSC, Christopher R Forrest MD MSc FRCSC, \\ Dalal Assaad MD FRCPC, Ida Ackerman MD FRCPC \\ Division of Plastic Surgery, Departments of Dermatology, Pathology and Radiation Oncology, \\ Skin Cancer Clinic, Toronto Bayview Regional Cancer Clinic, Toronto, Ontario
}

\begin{abstract}
CH Karsli, OM Antonyshyn, CR Forrest, D Assaad, I Ackerman. Malignant tumours of the external ear. Can J Plast Surg 1994;1(4):177-183. This study employs a retrospective chart review to describe the demographic features, clinical presentation and treatment of malignant tumours of the external ear. This series includes 129 tumours of the external ear in as many consecutive patients presenting to the Toronto Bayview Regional Cancer Centre between January 1986 and December 1991. Sixty-seven per cent of those tumours were basal cell carcinomas, $32 \%$ were squamous cell carcinomas, and a single case of Kaposi's sarcoma was encountered. The majority of patients was male and the mean age was 70.1 years. The helical rim was the most common site of involvement, followed by the postauricular, conchal and antihelical regions. Small tumours were located in the visually obvious areas of the ear, namely the helix and lobule, whereas larger tumours were found in the deeper central portions such as the concha and external auditory meatus. Twelve per cent of squamous cell carcinomas were metastatic at the time of treatment. Treatment methods included electrodesiccation and curettage, surgical excision with or without frozen sections, radiotherapy or combination therapy. Surgical excision, with frozen section control in carefully selected cases, remains the treatment of choice for the majority of external ear tumours. Various methods of reconstruction of the resulting defects are described.
\end{abstract}

Key Words: External ear, Skin tumours

\section{Tumeurs malignes de l'oreille externe}

RÉSUMÉ : Cette étude se sert d'une rétrospective sous forme de tableaux pour décrire les caractéristiques démographiques, la présentation clinique et le traitement des tumeurs malignes de l'oreille externe. Cette série porte sur 129 tumeurs de l'oreille externe chez autant de patients consécutifs admis au Toronto Bayview Regional Cancer Centre, entre janvier 1986 et décembre 1991. Soixante-sept pour cent de ces tumeurs étaient des carcinomes basocellulaires, $32 \%$ des épithéliomes, et un seul cas de sarcome de Kaposi a été rencontré. La majorité des patients était des hommes, dont la moyenne d'âge était de 70,1 ans. Le rebord hélicoïdal était le foyer le plus souvent en cause, suivi des régions postauriculaires du cornet et de l'anthélix. Les petites tumeurs étaient situées dans des zones visibles de l'oreille, nommément l'hélix et le lobule, alors que les tumeurs plus volumineuses se trouvaient dans les portions centrales plus profondes, comme le cornet et le conduit auditif externe. Douze pour cent des épithéliomes étaient métastatiques au moment du traitement. Les méthodes thérapeutiques comprenaient l'électrodessication et le curetage, l'excision chirurgicale avec ou sans sections congelées, la radiothérapie ou un traitement d'association. L'excision chirurgicale avec sections congelées dans certains cas sélectionnés demeure le traitement de choix pour la majorité des tumeurs de l'oreille externe. Diverses méthodes de reconstruction et les déformations qui en résultent sont décrites.

$\mathrm{M}$ alignant tumours of the external ear consist primarily of basal cell carcinomas and squamous cell carcinomas. Basal cell carcinomas make up roughly $75 \%$ of those tumours (1), and approximately $80 \%$ of tumours are found in men, most commonly in the sixth and seventh decades of life (2).

The most common sites of involvement include the helical rim, followed by postauricular, conchal, antihelical and lobule region (3). Although basal cell carcinomas are rarely metastatic at the time of initial treatment, metastases are found in 6 to $13 \%$ of squamous cell carcinomas (4).

This study outlines the clinical features and demographic characteristics of common external ear tumours. In addition,

Correspondence and reprints: Dr Oleh M Antonyshyn, Sunnybrook Health Science Centre, Room 271, H-Wing Second Floor, 2075 Bayview Avenue, Toronto, Ontario M4N 3M5. Telephone (416) 480-4868, Fax (416) $480-6800$ various treatment options and methods of reconstruction are presented.

\section{THE SERIES}

All patients presenting to the Toronto Bayview Regional Cancer Clinic (TBRCC) between January 1986 and December 1991 with primary skin tumours involving the external ear were included in the study. The series comprised 129 tumours in as many consecutive patients. There were 118 men and 11 women, ranging in age from 31 to 94 years, with a mean age of 70.1 years.

\section{METHODS}

\section{TBRCC protocol}

All patients with lesions of the external ear referred to the TBRCC are assessed in the Skin Cancer Clinic by a multidisciplinary team. Decisions regarding diagnosis and management 


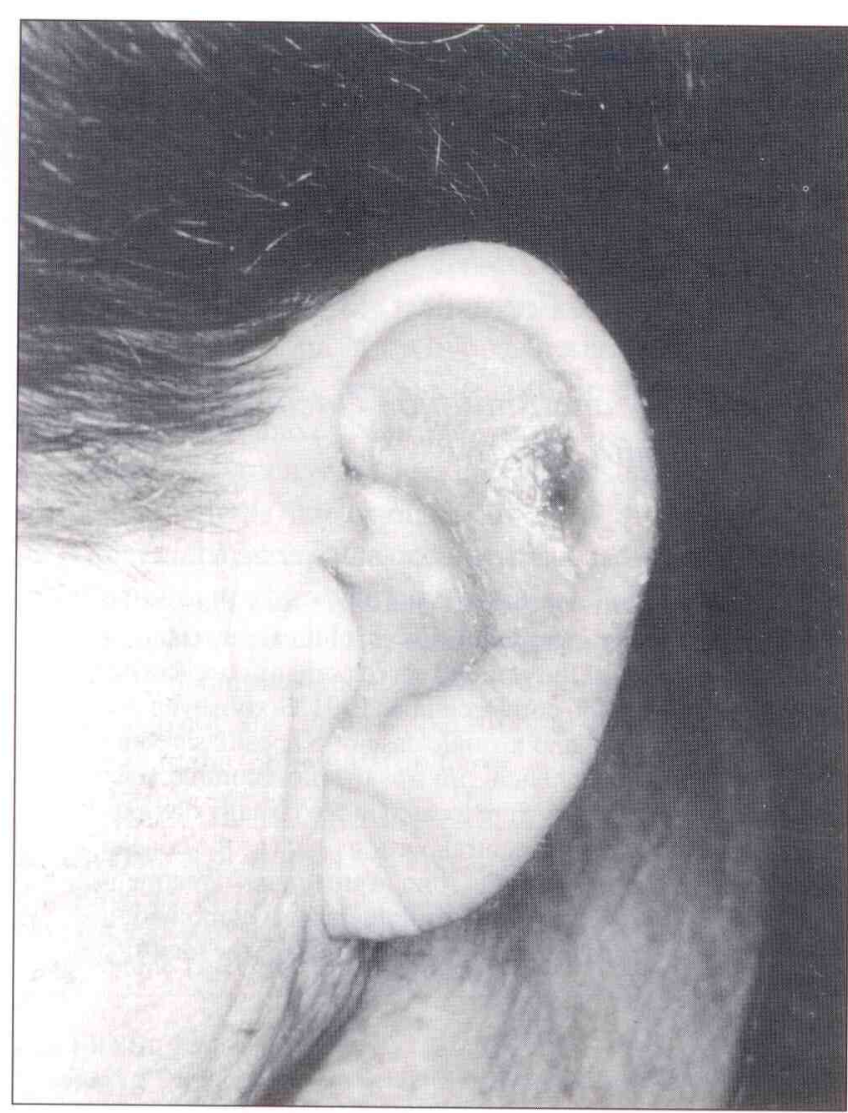

Figure 1) Basal cell carcinoma, left ear. Note faint nodular margin and central ulceration

of patients are made jointly by plastic surgeons, a dermatologist, a radiation oncologist and a dermatopathologist.

A standard protocol is followed in all cases. A biopsy of the lesion is first performed to obtain a pathological diagnosis. The tumour type, size and anatomical location, the presence or absence of regional metastases and individual patient factors are taken into consideration in making recommendations for treatment.

Treatment options employed at the TBRCC include electrodessication and curettage, surgical excision, radiotherapy and combination therapy. In specific cases, where the tumour is recurrent or tumour margins are indistinct, surgical excision is recommended in conjunction with frozen section control of margins and depth.

The method of charting at the cancer clinic is comprehensive, and each chart includes a clinical note on the patient's history as well as a complete description of the skin lesion (ie, size, type and anatomical location). Tumours are histologically verified, and an operative note describes the method of treatment, size of surgical defect and the method of reconstruction.

\section{Retrospective study}

This study is based on a retrospective chart review, in which a standardized data sheet was employed in recording patient demographic information, tumour description, treatment modality and method of reconstruction. These data

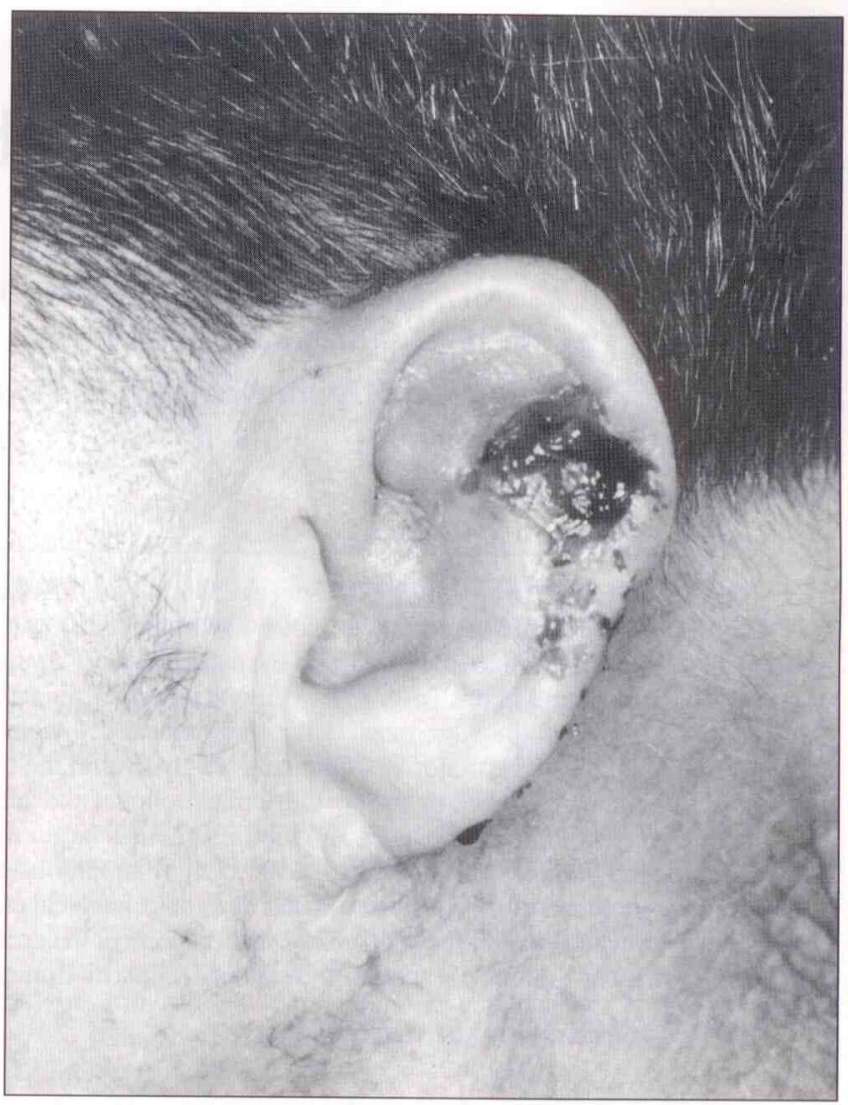

Figure 2) Squamous cell carcinoma, left ear. Note ulceration and exposed cartilage, and indurated, ill-defined margin extending to helical rim, scapha and concha of the ear

were entered and analyzed in a database program (Filemaker Pro, Claris Corp) on a Macintosh computer.

\section{RESULTS}

\section{Histopathology}

Eighty-seven $(67 \%)$ of the tumours in this series were basal cell carcinomas (Figure 1), with 41 (32\%) being squamous cell carcinomas (Figure 2). There were no cases of melanoma encountered during the study period, however, a single case of Kaposi's sarcoma in a human immunodeficiency virus-positive patient was documented.

\section{Tumour size and location}

Forty-seven per cent of the tumours originated in the right ear, and 53\% were in the left. Figure 3 represents the anatomical distribution of all tumours, basal cell carcinomas and squamous cell carcinomas, respectively.

Primary tumour sizes ranged from less than $2 \mathrm{~mm}$ to over $50 \mathrm{~mm}$ in diameter. Mean diameter of basal cell carcinomas was $13.9 \mathrm{~mm}$, and that of squamous cell carcinoma was 16.6 $\mathrm{mm}$. Figure 4 diagrammatically represents the mean diameter of tumours at presentation in various anatomical locations.

\section{Local invasion and metastases}

Nine of the 129 tumours extended beyond the external ear (Figure 5). Seven of these were squamous and two were basal 

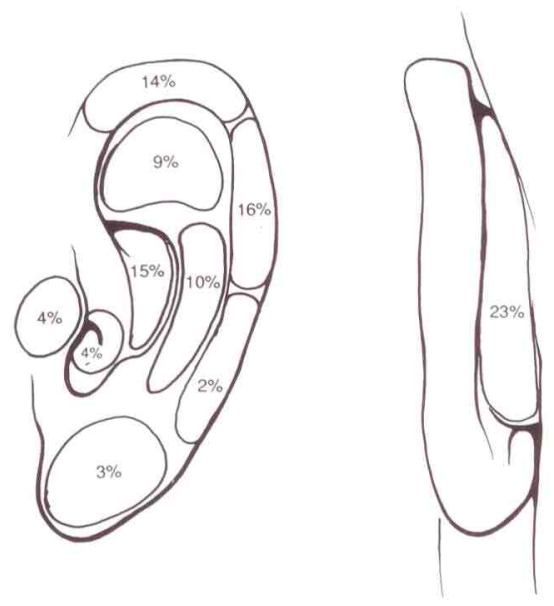

cell carcinomas, with an overall mean diameter of $30 \mathrm{~mm}$. Common sites of involvement included the face, middle ear, mastoid bone and parotid gland. Five of these tumours, all squamous cell carcinomas, involved metastases to cervical lymph nodes.

\section{Treatment}

All of the patients in this series received treatment, with the exception of one case of recurrent and widespread squamous cell carcinoma, in which radical surgery had previously been performed and the patient had refused any further treatment.

Modalities of treatment included electrodessication and curettage, surgical excision, radiation, and a combination of surgery and radiation (Table 1). Only eight of the 129 tumours were treated by curettage. These tumours tended to be small, with a mean diameter of $4.0 \mathrm{~mm}$. The majority of tumours in this series $(63 \%)$ was treated surgically. Of the surgically treated tumours, $28 \%$ were excised under frozen section control. These tumours tended to be larger (mean diameter $19.1 \mathrm{~mm}$ ) than those excised without the use of frozen sectioning (mean diameter $12.1 \mathrm{~mm}$ ). The concha or external auditory meatus was involved in $25 \%$ of the tumours excised under frozen section control, whereas only $12 \%$ of the tumours excised without the use of frozen sectioning involved these deeper, concealed areas of the external ear.

Radiation alone was used to treat $20(16 \%)$ of the tumours. Forty-five per cent of these tumours were located in the deep central portions of the external ear (concha and external auditory meatus). Eleven of 20 tumours were larger than 20 $\mathrm{mm}$ in diameter, and there were three cases of multifocal disease in this treatment group.

Combined therapy, involving surgical excision with postoperative radiation, was used in only $4 \%$ of cases, and these tumours were substantially larger (mean diameter $35.2 \mathrm{~mm}$ ) than those treated by other modalities. Sixty per cent of tumours in this treatment group were squamous cell carcinomas.
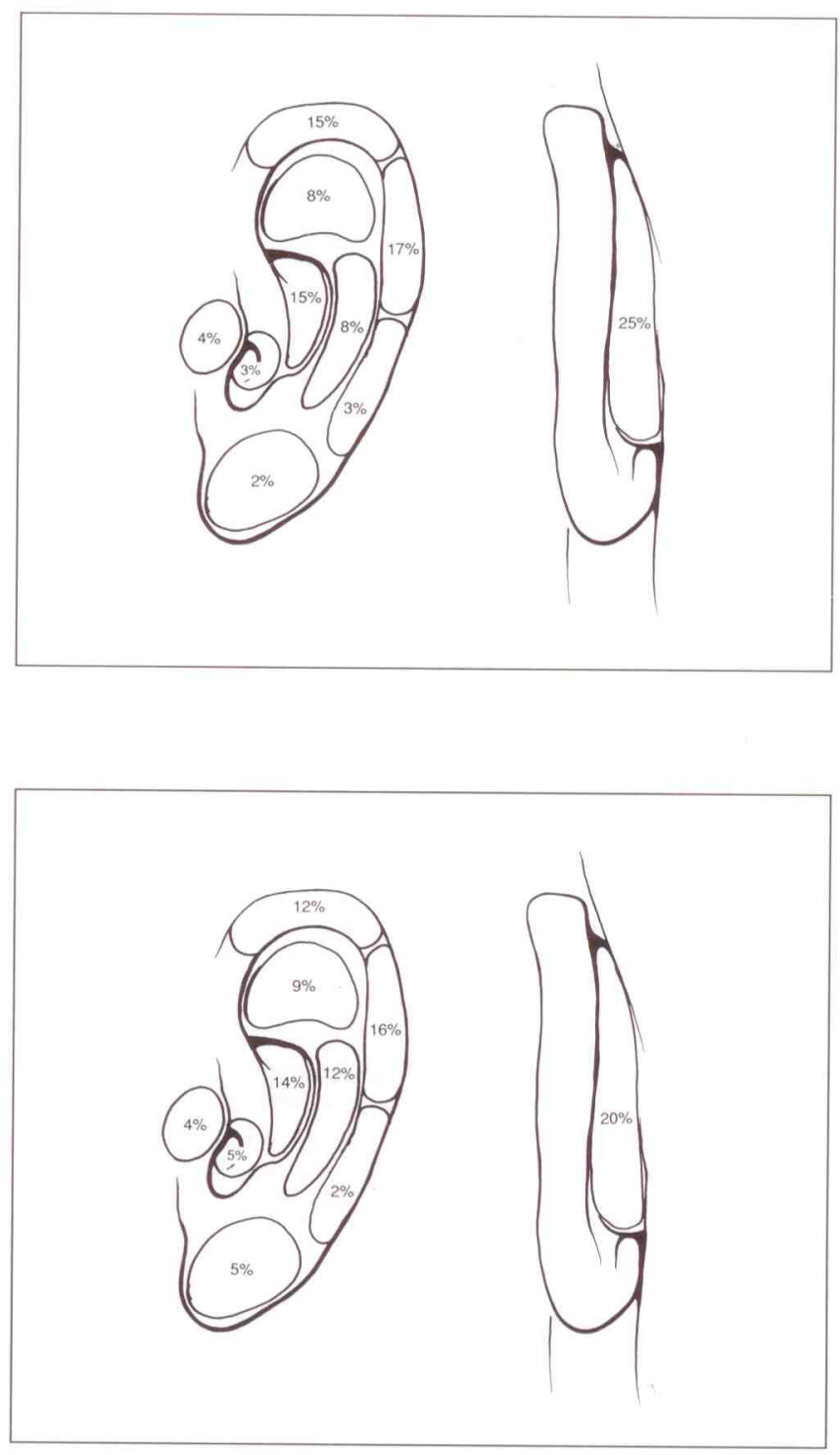

Figure 3) Anatomical distribution of malignancies of the external ear. Per cent distribution of all malignancies (above left); Per cent distribution of basal cell carcinoma (above right); Per cent distribution of squamous cell carcinoma (below right)

\section{Reconstruction}

Ninety-nine patients in this series underwent surgical excision of their external ear tumour. The specific modality of reconstruction depended on the anatomical location and size of defect.

The majority $(56 \%)$ of defects were closed simply by direct approximation (elliptical or wedge excision followed by primary closure). These tumours averaged $10.2 \mathrm{~mm}$ in diameter. Fifty-eight per cent were helical rim defects, and $20 \%$ were postauricular defects.

Skin or composite grafts were used to reconstruct surgical defects in 17 of 99 cases. These tended to be larger defects (mean diameter $24.3 \mathrm{~mm}$ ), and the majority involved sites other than the helical rim, ie, antihelix, concha and external auditory meatus (Figure 6).

More substantial defects, in particular those that were 
TABLE 1: Modalities of treatment

\begin{tabular}{lccccc}
\hline & Curettage & Surgical excision + FS & Surgical excision - FS & Surgery + radiation & Radiation \\
\hline Number of cases & 8 & 26 & 68 & 5 & 21 \\
Mean diameter & 4.0 & 19.1 & 22 & 12.1 & 35.2 \\
Number of BCC & 4 & 4 & 46 & 2 & 16.4 \\
Number of SCC & 4 & 22 & 3 & 7 \\
\hline
\end{tabular}

BCC Basal cell carcinomas; FS Frozen sections; SCC Squamous cell carcinomas

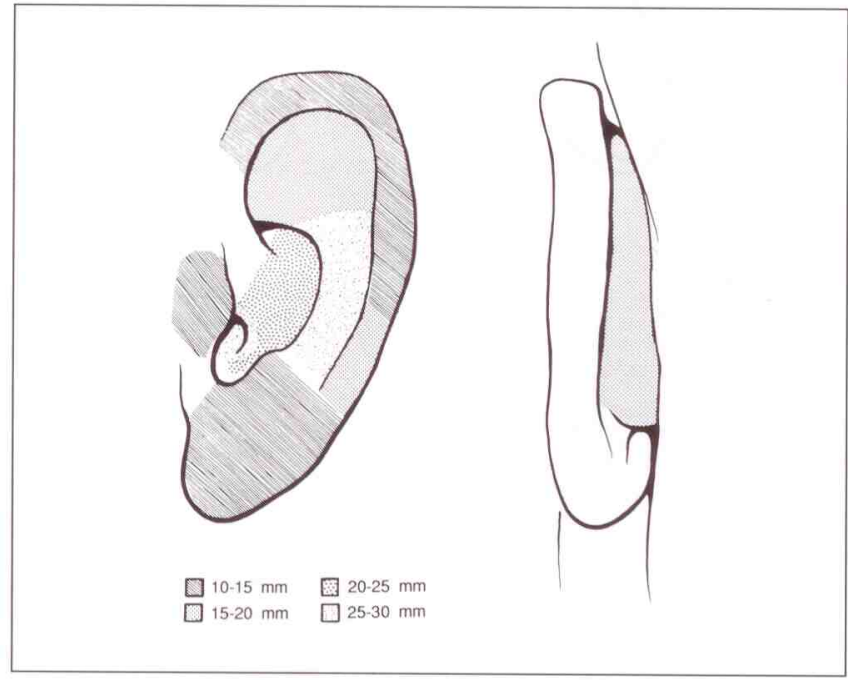

Figure 4) Schematic diagram indicating the average size of malignancies at presentation in different anatomical locations of the external ear

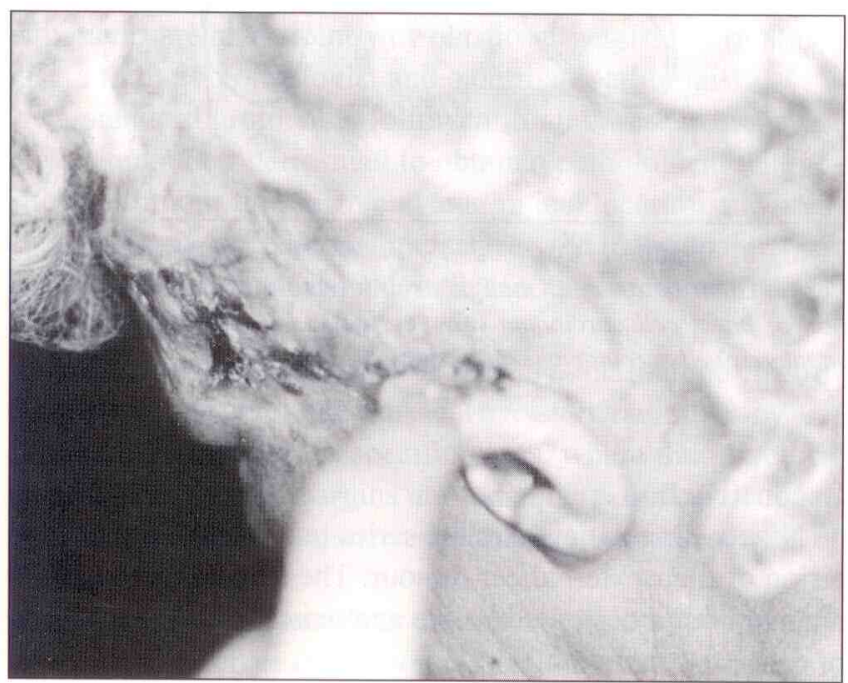

Figure 5) Patient with primary basal cell carcinoma involving the superior pole of the left ear. Note extensive local infiltration of the temporal and parietal scalp and mastoid regions

associated with a composite deficiency of skin and key anatomical elements of the cartilaginous framework, were reconstructed with local skin or chondrocutaneous flaps (Figure 7). Flap reconstruction was required in $26 \%$ of defects of the external ear.

\section{DISCUSSION}

Malignant tumours of the external ear have a notorious reputation for being overlooked and undertreated, and, as a result, tend to recur more frequently than malignant skin tumours elsewhere on the body (2). Failure rates for treatment of squamous cell carcinoma have been shown to be five times higher than those of the skin in general (6). This discrepancy may be due to the overly conservative approach to external ear tumours. For these reasons, primary care physicians should be aware of some of the demographic and clinical characteristics of external ear tumours. They should also be familiar with treatment options available to their patients, as well as basic concepts of external ear reconstruction.

The majority of patients with tumours of the external ear treated at our centre were males in their seventh decade of life. This may be attributed to greater sun exposure and lack of hair cover over the ears. Two-thirds of the tumours were basal cell carcinomas, despite the belief by some that external ear tumours are predominantly squamous $(5,6)$.

The helical rim was the most common site of involvement, followed by the postauricular region, the concha, antihelix, scapha, external auditory meatus and lobule. Very similar findings were noted by Mohs et al (7). The anatomical distribution of squamous and basal cell carcinoma was almost identical. The incidence of tumour in various anatomical sites reflects greatest involvement of those areas predisposed to the greatest degree of sun exposure.

The smallest tumours were located along the helical rim and lobule. Since these are the most visually obvious areas of the external ear, presumably these patients would seek medical attention at earlier stages of tumour growth. Postauricular tumours may cause irritation and bleeding early, particularly in those patients wearing eyeglasses, and, as such, tumours in this location were also small at presentation. The largest tumours were located in the deeper, less noticeable areas of the external ear, namely the external auditory meatus and concha. More meticulous clinical assessment and early detection should decrease the need for more extensive surgery and minimize the possibility of spread.

Local invasion was seen in both basal and squamous cell carcinoma, but only the latter demonstrated metastases $(12 \%$ of squamous cell carcinomas were metastatic). This is in keeping with the tendency of basal cell carcinoma to be a slowly growing locally invasive tumour, whereas squamous cell carcinoma tends to metastasize more commonly (8).

Although electrodessication and curettage has traditionally been the most common method of treating basal cell 


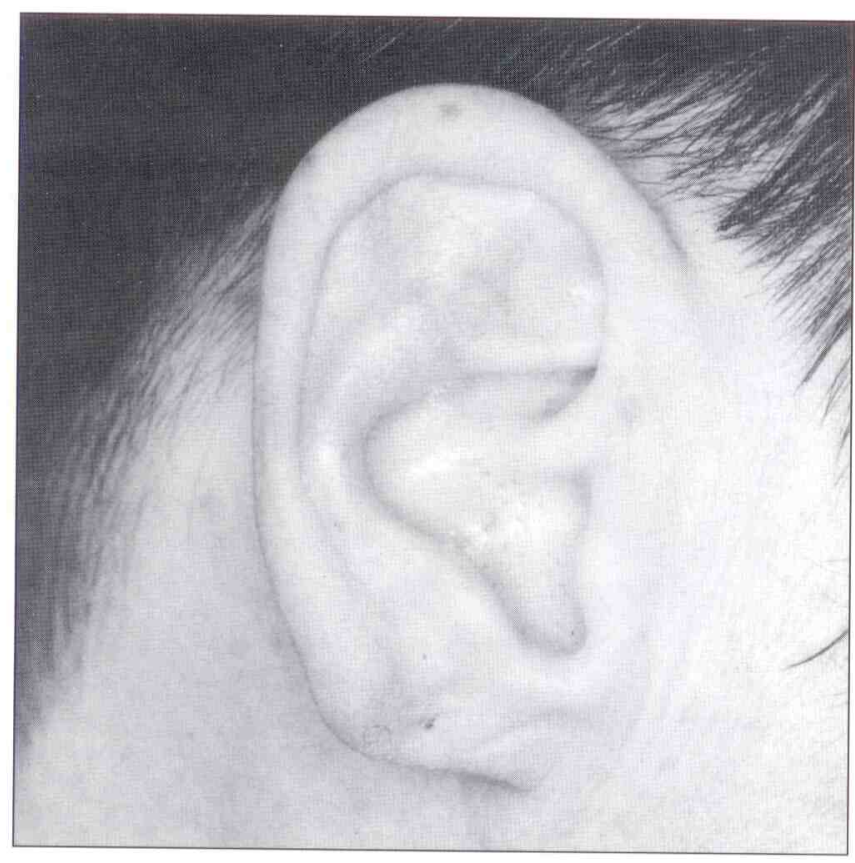

carcinomas, it is not recommended for lesions greater than 2 $\mathrm{cm}$ in diameter, those over bone or cartilage, or for tumours with indistinct margins such as sclerosing basal cell carcinoma (9). Since the technique of electrodessication and curettage is associated with recurrence rates as high as $41 \%$ (10), it should be reserved for small nonsclerosing tumours in which surgical excision is not a reasonable option.

The treatment of choice for the majority of external ear tumours is surgical excision. The lack of subcutaneous tissue in the external ear allows perichondrial involvement and fixation to occur early, with projection of tumour along subcutaneous tissue planes. This is especially true of basal cell carcinoma, which tends to spread superficially but irregularly along perichondrium. In addition, margins of sclerosing basal cell carcinoma are indistinct, and ulcerative lesions tend to extend with finger-like projections or multifocally rather than maintaining spherical growth patterns (10). For these reasons, excision of skin and underlying cartilage has been advocated for tumours involving perichondrium.

Excision of tumour under frozen section control provides confirmation of complete removal by pathological examination, and is frequently used for large or recurrent tumours, tumours with indistinct borders, deep penetration, or those that are not easily visualized. Very extensive tumours may require surgery with postoperative radiation. All metastatic tumours treated in this series were managed using this combination therapy. Radiation alone may be used in patients refusing, or who are unfit for, surgery. Large tumours involving the deep central parts of the external ear may also be treated in this manner, particularly if surgical excision would result in gross disfigurement with little chance of acceptable reconstruction.

Defects amenable to primary closure include small elliptical and wedge defects, and those involving the lobule or postauricular area. Although direct approximation of helical
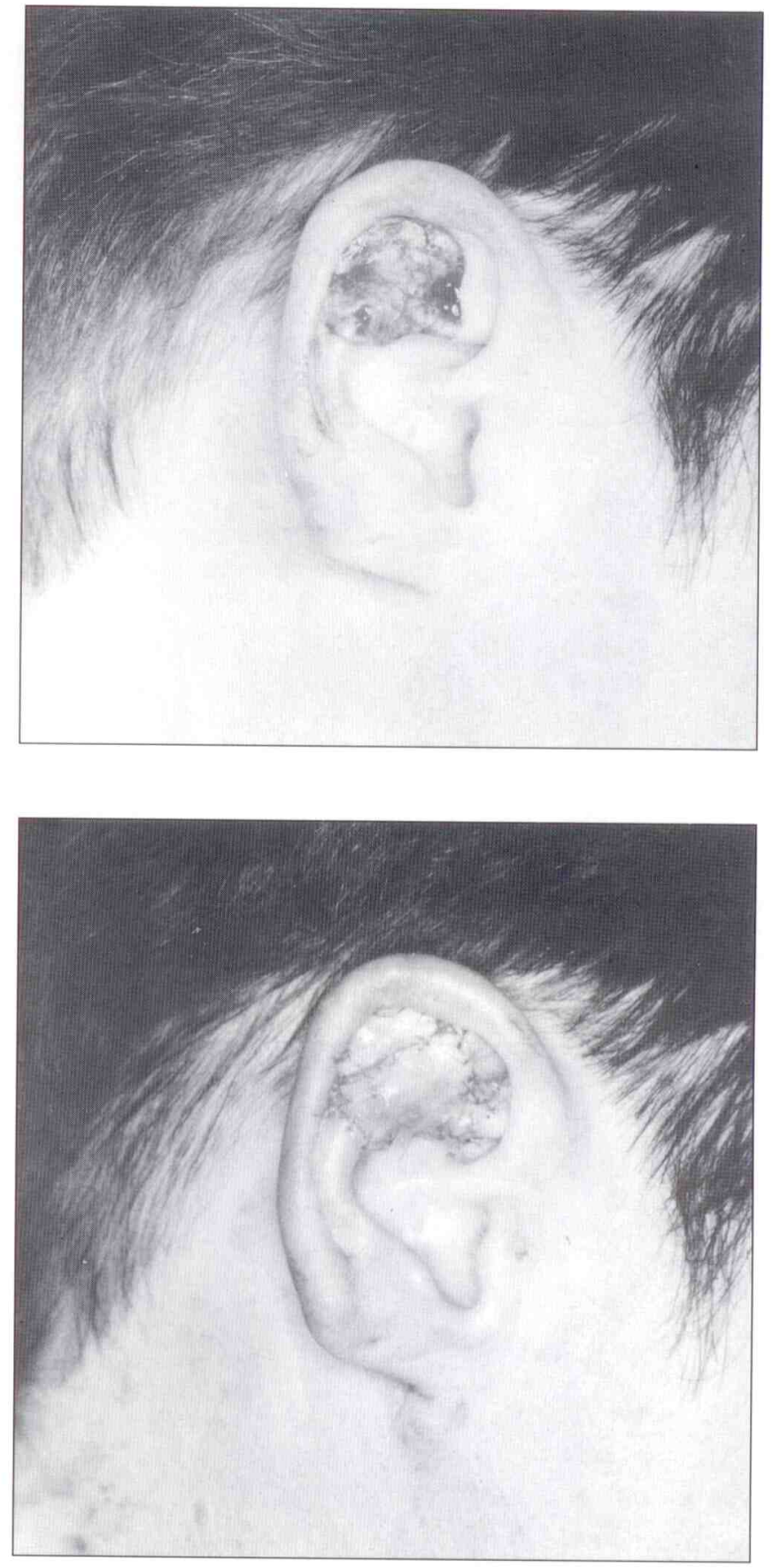

Figure 6) Sclerosing basal cell carcinoma, scapha right ear. Tumour presents as an erythematous sclerotic plaque with indistinct margins (above left). Tumour excision was performed under frozen section control (above right). The resulting defect involves most of the scapha, but the underlying cartilage and perichondrium are preserved; the defect is reconstructed with a full-thickness graft (below right)

rim wedge defect edges results in a smaller ear, the cosmetic result is nevertheless quite acceptable. Helical rim defects may also be successfully reconstructed using chondrocutaneous advancement flaps as described by Antia (11). In this technique, local tissues are advanced along the helical rim both superiorly and inferiorly, resulting in a normally contoured, albeit smaller, ear. Obvious size discrepancies 

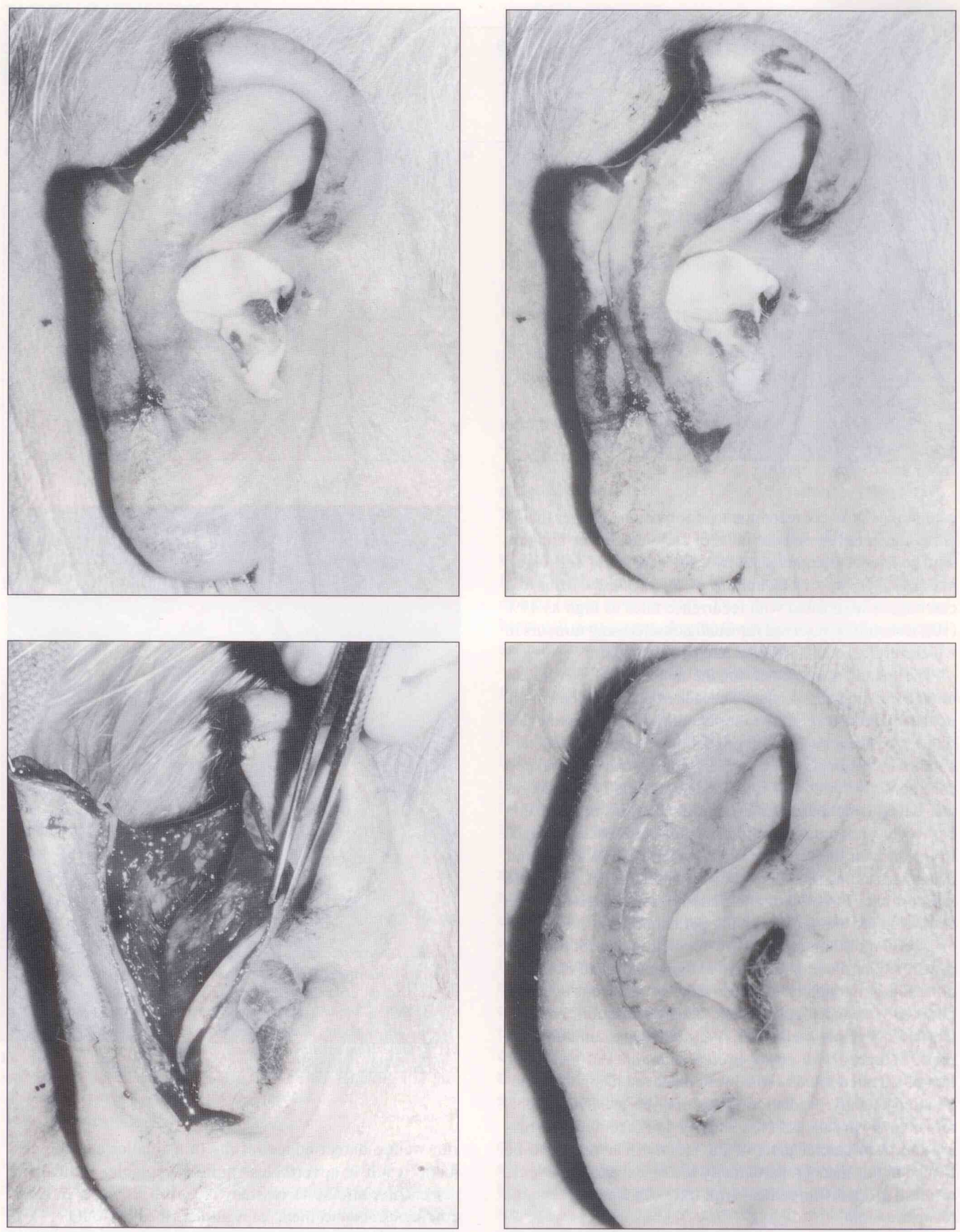

Figure 7) Defect helical rim right ear resulting from excision of basal cell carcinoma (above left). Flap reconstruction planned and marked out (above right). Chondrocutaneous flaps are elevated by incising and raising the entire helical rim based on a postauricular skin pedicle to permit rotation and closure of the defect (below left). Result, two weeks postoperatively (below right) 
may be corrected by performing a wedge excision of the contralateral ear, although this is usually not necessary.

Larger defects involving areas other than the helical rim might benefit from skin grafting, which tends to preserve the size and contour of the ear. Although grafts to the helical rim usually take, later scar contraction will usually result in a distorted or crumpled helical rim (10). The concha and external auditory meatus take grafts particularly well, and result in minimal distortion. Common skin graft donor sites include the neck and mastoid region.

\section{REFERENCES}

1. Leferink VJM, Nicoloi JP. Malignant tumors of the external ear. Ann Plast Surg 1988;21:550-3.

2. Lin JC, Chen KY, Jan JS, Wu YP, Jame JM. Cancer of the auricle. Chin Med J 1990;45:233-40.

3. Niparko JK, Swanson NA, Baker SR, Telain SA, Sullivan MJ, Kemink JL. Local control of auricular, preauricular, and external canal cutaneous malignancies with Mohs surgery. Laryngoscope 1990;100:1047-51.

4. Gibson EW. Malignant tumors of the skin. In: Grabb WC, Smith TW, eds. Plastic Surgery, 3rd edn. Boston: Little, Brown, 1980.

5. Blake, JB, Wilson JSP. Malignant tumors of the ear and their treatment.
Local skin flaps, including preauricular and mastoid flaps, have been used to resurface postauricular, conchal and helical root defects. The relative laxity of preauricular and mastoid skin makes these areas excellent donor sites. More complex procedures, including myocutaneous and cartilage grafts, may be necessary for extensive defects. These procedures, however, are often carried out in multiple stages, are time-consuming and require general anesthesia. For these reasons, their use in the elderly patient with skin cancer may be limited.

Br J Plast Surg 1984;67:308-11.

6. Shiffmon NJ. Squamous cell carcinomas of the skin of the pinna. Can J Surg 1975;18:279-83.

7. Mohs F, Larson P, Iriondo M. Micrographic surgery for the microscopically controlled excision of carcinoma of the external ear. J Am Acad Dermatol 1988;19;729-37.

8. Barton FE. Cutaneous malignancies I: Basal cell and squamous cell carcinoma. Sel Readings Plast Surg 1982;2:1-28.

9. Freeman RG, Knox JM, Heaton CL. The treatment of skin cancer. Cancer 1964;17:535-43.

10. Menick FJ. Reconstruction of the ear after tumour excision. Clin Plast Surg 1990;17:405-15. 